\title{
Peptides Identified Through Phage Display for Prostate Cancer Imaging and Therapy
}

\author{
Wei Wang $^{1^{*}}$, Moze Tong ${ }^{1}$, Yanbin Zhang ${ }^{1}$ and Yongping Chen ${ }^{1,2}{ }^{*}$ \\ ${ }^{1}$ Department of Urology, the Second People's Hospital of Hefei, Hefei 230011, Anhui, PR China \\ ${ }^{2}$ Washington Biotechnology Inc, 6200 Seaforth Street, Baltimore, Maryland 21224, USA
}

"Corresponding author: Yongping Chen, W ashington Biotechnology Inc, 6200 Seaforth Street, Baltimore, Maryland 21224, USA, T el: +1 410-633-9210; E-mail: yongpingchen686@gmail.com

Received date: October 26, 2015; Accepted date: October 27, 2015; Published date: November 02, 2015

Copyright: @ 2015 Wang W, et al. This is an open-access article distributed under the terms of the Creative Commons Attribution License, which permits unrestricted use, distribution, and reproduction in any medium, provided the original author and source are credited.

\begin{abstract}
Prostate cancer is the second highest cause of cancer death among the world. It is important to identify the target molecules for prostate cancer early detection and targeted therapy. In this mini review, we discuss some of peptides identified through phage display for molecular imaging and targeted therapy of prostate cancer.
\end{abstract}

Keywords: Prostate cancer; Peptides; Molecular imaging; Targeted therapy; Phage display

\section{Editorial}

Cancer has become the second most common cause of the death following cardiovascular disease in the world [1]. A few millions people are diagnosed with cancer every year around worldwide, and many patients eventually die from it. For example, in the United States, approximately 1,600 people die from cancer every day. Among these, prostate cancer (PCA) is the most common cancer among men in the USA. The approximately 2 million cases and around 0.3 million prostate cancer related deaths occurred in the United States in 2013 [2]. So far, the prostate cancer is the second highest cause of cancer death among the world.

In the future, estimates of diagnosed prostate cancer cases are around $16.48 \%$ of men at some point during their lives [3]. There are tens of thousands of individuals who suffer the symptoms of aggressive prostatic cancer, which affects the quality of life of people even they may not die by cause of it. Although, the PSA (prostate specific antigen) test has been used initial diagnosis of disease or monitor the efficacy of therapy and for prognosis of outcomes [4]. Even a man has abnormal level of PSA in the blood, doctors still would often recommend a prostate biopsy to determine whether prostate cancer is present, but biopsy is an invasive method. Therefore, the development of non-invasive technologies with the goal to detect prostate cancer at early, monitor therapeutic effects and treatment outcomes, and guide interventions are urgent for such patients. Molecular imaging is considered as this novel method.

Molecular imaging is a type of medical imaging that provides detailed pictures of what is happening inside the body at molecular and cellular level. It would be used to identify prostate cancer in its earliest stages and detect the exact location of a tumour in prostate before symptoms occur. Molecular imaging combined with targeted therapy are two edged sword that may improve the efficiency of diagnosis, attenuate prostate cancer growth, reduce the side of chemotherapy and extend survival of prostate cancer patients. Whatever molecular imaging or targeted therapy of prostate cancer, they focus on molecular targets. So, identifying targets plays essential roles in designing new diagnosis or therapeutic agents. Phage display has opened the door to development of these agents in prostate cancer imaging or targeted therapy.

Phage display is a powerful tool in which a peptide or protein is genetically fused to a coat protein of a bacteriophage, resulting in display peptide or protein on the surface of phage particles $[5,6]$. Usually, this technique is used to study the interactions between protein-protein, protein-peptide, and protein-DNA [7]. Also, this technique is for selecting peptides, proteins, or antibodies with specific binding with receptors or particular molecules. Compared to antibody, identifying of peptide is more interesting to researchers because of their rapid blood clearance, tissue penetration, increased diffusion, non-immunogenic nature and easily synthesis. [8]. Different screening methods have allowed to identify the peptides binding to specific molecules in vitro, in living cancer cells, in animals or in human samples [9-11]. Recently, this technique is great interesting in cancer area to select specific peptides for targeting including prostate cancer. The focus here is centered to "targets" related to peptides identified through phage display binding to the receptor or antigen on the surface of the prostate cancer for prostate cancer molecular imaging and targeted therapy.

Phage display was widely used to identify peptides to develop new peptide-based probes for optical molecular imaging of prostate cancer. Near-infrared (NIR) optical imaging has increasingly interesting for disease detection, therapeutic effects monitoring, and interventions guiding due to minimal autofluorescence, low absorption and significant imaging depth in vivo [12-14]. With these advantages of NIR imaging, it is very useful to develop peptide-based molecular NIR probes for prostate cancer diagnosis. Toward this goal, Newton et al. [15] used in vivo phage display method to identify the peptide sequence IAGLATPGWSHWLAL to bind PC-3 human prostate carcinoma, and demonstrated the phage clone labeled with the NIR fluorophore AlexaFluor680 had a tumor-to-muscle ratio of $\sim 30$ in experiments. In addition, Kelly et al. [16] used phage display to isolate Hepsin (HPN: as a biomarker for detection of PCA) binding peptides with high affinity and specificity, and they developed HPN targeted NIR imaging agents, which binds HPN with high specificity within prostate cancer in vivo. Compared to NIR imaging, Magnetic 
resonance imaging (MRI) has the advantages of having very high spatial resolution and is very adept at morphological imaging [17].

The peptide targeted contrast agents are promising for highresolution molecular MRI of prostate cancer. Wu et al. synthesized and evaluated a small molecular targeted contrast agent using a pentapeptide CREKA as a target molecule named CREKA-dL-(GdDOTA)4 with improved physico-chemical and pharmaceutical properties for molecular MRI imaging of prostate cancer [18]. Recently, Ghosh et al. engineered a phage-displayed peptide that targets SPARC glycoprotein, which is highly expressed in prostate cancer to M13 surface with assembly of monodisperse iron oxide magnetic nanoparticles and demonstrated that M13-templated magnetic nanoparticles were used for targeted in vivo imaging of prostate cancer [19]. Besides these imaging methods, many investigations have been conducted using diagnostic radiotracer specific for prostate cancer imaging. Based on phage-displayed peptide contrast agents, Faintuch et al. compared two peptide radiotracers for prostate carcinoma targeting and imaging and demonstrated that peptide radiotracers are promising for prostate cancer imaging [20].

After we mentioned the strategy of molecular imaging for prostate cancer based on phage displayed peptide, we will briefly discuss the targeted therapy of prostate cancer using peptide identified through phage display as target molecules. Two peptides, PKRGFQD and SNTRVAP were identified through phage display by Mandelin et al. [21] targeting a model of castrate-resistant osteogenic prostate cancer in vivo, which should be considered for targeted drug development for therapy of human metastatic androgen-independent prostate cancer Also, Shen et al, identified peptides as ligands for Prostate-specific Membrane Antigen (PSMA) and evaluated the binding of prostate cancer. These peptide sequences might as the target for prostate cancer tumor imaging and therapy [22]. Recently, DePorter et al, engineered M13 bacteriophage nanocarriers for intracellular delivery of exogenous proteins to human prostate cancer cells which would be used to deliver payload for therapy of prostate cancer [23].

In this editorial, we summarized some examples where peptides were identified through phage display to engineer contrast agents for prostate cancer imaging or targeted therapy of prostate cancer. We hope readers realize identification of the binding peptides isolated from phage display is of high importance and open a new view for readers.

\section{References}

1. Ferlay J, Autier P, Boniol M, Heanue M, Colombet M (2007) Estimates of the cancer incidence and mortality in Europe in 2006. Annals of oncology 18: 581-592.

2. Jemal A, Siegel R, Ward E, Murray T, Xu J, et al. (2007) Cancer statistics. CA Cancer J Clin 57: 43-66.

3. Howlader N, Noone AM, Krapcho M, Neyman N, Aminou R et al. (2011) SEER Cancer Statistics Review, 1975-2008. National Cancer Institute.

4. Caplan A, Kratz A (2002) Prostate-specific antigen and the early diagnosis of prostate cancer. Am J Clin Pathol 117: S104-S108.
5. Sidhu SS (2001) Engineering M13 for phage display. Biomolecular engineering 18: 57-63.

6. Willats WG (2002) Phage display: practicalities and prospects. Plant molecular biology 50: 837-854.

7. Barbas CF, Burton DR, Scott JK, Silverman GJ (2004) Phage display: a laboratory manual. CSHL Press.

8. Deutscher SL (2010) Phage display in molecular imaging and diagnosis of cancer. Chemical reviews 110: 3196-3211.

9. Pasqualini R, Ruoslahti E (1996) Organ targeting in vivo using phage display peptide libraries. Nature 380: 364-366.

10. Schier R, Marks JD, Wolf EJ, Apelld G, Won C, et al. (1995) In vitro and in vivo characterization of a human anti-c-erbB-2 single-chain Fv isolated from a filamentous phage antibody library. Immunotechnology 1: 73-81.

11. Michon IN, Hauer AD, von der Thüsen JH, Molenaar TJ, van Berkel TJ et al. (2002) Targeting of peptides to restenotic vascular smooth muscle cells using phage display in vitro and in vivo. Biochim Biophys Acta 1591: 87-97.

12. Ke S, Wen X, Gurfinkel M, Charnsangavej C, Wallace S, et al. (2003) Nearinfrared optical imaging of epidermal growth factor receptor in breast cancer xenografts. Cancer Res 63: 7870-7875.

13. Hilderbrand SA, Weissleder R (2010) Near-infrared fluorescence: application to in vivo molecular imaging. Curr Opin Chem Biol 14: 71-79.

14. Frangioni JV (2003) In vivo near-infrared fluorescence imaging. Curr Opin Chem Biol 7: 626-634.

15. Newton JR, Kelly KA, Mahmood U, Weissleder R, Deutscher SL (2006) In vivo selection of phage for the optical imaging of PC-3 human prostate carcinoma in mice. Neoplasia 8: 772-780.

16. Kelly KA, Setlur SR, Ross R, Anbazhagan R, Waterman P, et al. (2008) Detection of early prostate cancer using a hepsin-targeted imaging agent. Cancer research 68: 2286-2291.

17. Brown G, Radcliffe AG, Newcombe RG, Dallimore NS, Bourne MW, et al. (2003) Preoperative assessment of prognostic factors in rectal cancer using highresolution magnetic resonance imaging. British Journal of Surgery 90: 355-364

18. Wu X, Yu G, Lindner D, Brady-Kalnay SM, Zhang Q, et al. (2014) Peptide targeted high-resolution molecular imaging of prostate cancer with MRI. American journal of nuclear medicine and molecular imaging 4: 525.

19. Ghosh D, Lee Y, Thomas S, Kohli AG, Yun DS, et al. (2012) M13templated magnetic nanoparticles for targeted in vivo imaging of prostate cancer. Nature nanotechnology 7: 677-682.

20. Faintuch BL, Oliveira EA, Nunez EG, Moro AM, Nanda PK, et al. (2012) Comparison of two peptide radiotracers for prostate carcinoma targeting. Clinics 67: 163-170.

21. Mandelin J, Cardó-Vila M, Driessen WH, Mathew P, Navone NM, et al. (2015) Selection and identification of ligand peptides targeting a model of castrate-resistant osteogenic prostate cancer and their receptors. Proceedings of the National Academy of Sciences 112: 3776-3781.

22. Shen D, Xie F, Edwards WB (2013) Evaluation of phage display discovered peptides as ligands for prostate-specific membrane antigen (PSMA). PloS one 8: e68339.

23. DePorter SM, McNaughton BR (2014) Engineered M13 Bacteriophage Nanocarriers for Intracellular Delivery of Exogenous Proteins to Human Prostate Cancer Cells. Bioconjugate chemistry 25: 1620-1625. 